\title{
The MEDESS-GIB database: tracking the Atlantic water inflow
}

\author{
Marcos García Sotillo ${ }^{1}$, Emilio Garcia-Ladona ${ }^{2}$, Alejandro Orfila ${ }^{3}$, Pablo Rodríguez-Rubio ${ }^{4}$, José \\ Cristobal Maraver ${ }^{5}$, Daniel Conti ${ }^{3}$, Elena Padorno ${ }^{1}$, José Antonio Jiménez ${ }^{2}$, Este Capó ${ }^{3}$, \\ Fernando Pérez ${ }^{2}$, Juan Manuel Sayol ${ }^{3}$, Francisco Javier de los Santos ${ }^{4}$, Arancha Amo ${ }^{1}$, Ana Rietz ${ }^{5}$, \\ Charles Troupin $^{6}$, Joaquín Tintore ${ }^{3,6}$, and Enrique Álvarez-Fanjul ${ }^{1}$ \\ ${ }^{1}$ Puertos del Estado, 28041 Madrid, Spain \\ ${ }^{2}$ ICM-CSIC, 08003 Barcelona, Spain \\ ${ }^{3}$ IMEDEA (CSIC-UIB), 07190 Esporles, Spain \\ ${ }^{4}$ Autoridad Portuaria Bahía de Algeciras, 11207 Algeciras, Spain \\ ${ }^{5}$ SASEMAR, 28011 Madrid, Spain \\ ${ }^{6}$ SOCIB, 07121 Palma de Mallorca, Spain \\ Correspondence to: Marcos García Sotillo (marcos@puertos.es)
}

Received: 2 July 2015 - Published in Earth Syst. Sci. Data Discuss.: 4 November 2015

Revised: 3 March 2016 - Accepted: 8 March 2016 - Published: 29 March 2016

\begin{abstract}
On 9 September 2014, an intensive drifter deployment was carried out in the Strait of Gibraltar. In the frame of the MEDESS-4MS Project (EU MED Program), the MEDESS-GIB experiment consisted of the deployment of 35 satellite tracked drifters, mostly of CODE-type, equipped with temperature sensor sampling at a rate of $30 \mathrm{~min}$. Drifters were distributed along and on both sides of the Strait of Gibraltar. The MEDESS-GIB deployment plan was designed as to ensure quasi-synoptic spatial coverage. To this end, four boats covering an area of about $680 \mathrm{NM}^{2}$ in $6 \mathrm{~h}$ were coordinated. As far as these authors know, this experiment is the most important exercise in the area in terms of number of drifters released. Collected satellite-tracked data along drifter trajectories have been quality controlled and processed to build the presented MEDESS-GIB database. This paper reports the MEDESS-GIB data set that comprises drifter trajectories, derived surface currents and in situ SST measurements collected along the buoys tracks. This series of data is available through the PANGAEA (Data Publisher for Earth and Environmental Science) repository, with the following doi:10.1594/PANGAEA.853701. Likewise, the MEDESS-GIB data will be incorporated as part of the Copernicus Marine historical products. The MEDESS-GIB data set provides a complete Lagrangian view of the surface inflow of Atlantic waters through the Strait of Gibraltar and thus, very useful data for further studies on the surface circulation patterns in the Alboran Sea, and their links with one of the most energetic Mediterranean Sea flows: the Algerian Current.
\end{abstract}

\section{Introduction}

Ocean surface dynamics are essential to understand the ocean's role in many key processes of the Earth's climate, as the ocean-atmosphere interactions or the global transport and redistribution of mass and energy (GCOS, 2010). Furthermore, the knowledge of ocean surface velocities is crucial and transversal to many socio-economic areas such as fisheries, global marine trade and shipping, marine safety and pollution, to mention a few.
The monitoring of ocean circulation is necessary to understand and ultimately forecast a variety of marine systems and applications, including coastal ecosystem management, search-and-rescue (SAR) operations and forecasting and mitigation of illegal or accidental discharge of pollutants. Satellite-tracked surface drifters are the only affordable technology that provides useful information on surface circulation both in deep ocean regions, within marginal seas and on continental shelves (Liu and Weisberg, 2011). 
From the pioneering work of John Swallow (Rossby, 2007), Lagrangian buoys have widely proved to be an appropriate instrument to study and to characterize large and mesoscale ocean currents, their influence on the ocean mixing as well as to infer the dynamical properties of the ocean surface. Since the beginning of satellite tracking in the early 1980s, drifters have been regularly used to observe surface currents over a wide range of scales, from tidal and/or inertial to interannual scales and from a few to thousands of kilometers. Lagrangian drifters move with the currents and can cover substantial geographical areas, providing useful data to understand near-surface dynamics with a relatively "lowcost" option for surveying large, poorly known areas of the oceans (Lumpkin and Pazos, 2007).

Extensive drifter experiments have been performed in different areas of the world either to characterize the surface circulation or to provide reference in situ data for model validation or for instrumental calibration purposes. Likewise, drifter observation provides very useful information for oil spill and search and rescue operations. Indeed, trajectories from Lagrangian drifter buoy data have been widely used as proxies of oil spills or floating objects on the ocean surface (Reed et al., 1994; Al-Rabeh, 1994; Price et al., 2006; García-Ladona et al., 2005; Barron et al., 2007; Sotillo et al., 2008; DeDominicis et al., 2013; Sayol et al., 2014).

The earliest deployments of drifters started in the Mediterranean Sea in 1986, allowing the study of multiple aspects of the surface dynamics in several areas, including interannual and seasonal variability of the ocean dynamics; basin, subbasin, and mesoscale circulation features; inertial and tidal currents; coastal circulation; and relative dispersion by surface waters. A broad review of important scientific results derived from these experiments with drifters, outlining quantitative descriptions of the surface circulation in the Mediterranean Sea, can be found in Poulain et al. (2013).

Apart from measuring surface currents, drifters are used in combination with numerical models to calibrate them or to check the quality of other observational devices, such as high-frequency (HF) radars. As stated in Lorente et al. (2015), HF-radar measurements are affected by intrinsic uncertainties (like radio wave interferences, antenna pattern distortions or environmental noise), and reliability of HFradar data has been previously tested in several validation studies including comparisons of HF-radar-derived surface currents with moored ADCP's, point-wise current meters and Lagrangian drifters (Ohlmann et al., 2007; Molcard et al., 2009; Shaden et al., 2009).

In recent years, there have been two major Mediterranean region initiatives, supported within the EU MED Programme, aimed to improve the quality and effectiveness of the decision-making process in case of maritime accidents in the Mediterranean Sea concerning oil spill pollution and SAR operations: TOSCA ("Tracking Oil Spills and Coastal Awareness network"; http://www.toscamed.eu) and MEDESS-4MS ("Mediterranean Decision Support System for Marine Safety"; http://www.medess4ms.eu/) projects. Both projects are quite complementary: TOSCA is focused on the observational component (HF-radars and drifter development) mainly in coastal areas (Bellomo et al., 2015), whereas MEDESS-4MS is more focused on the oil spill modeling component (Capó et al., 2015).

MEDESS-4MS is a project dedicated to the maritime risk prevention and strengthening of maritime safety related to oil spill pollution in the Mediterranean Sea. The ultimate objective of MEDESS-4MS is to deliver an integrated operational multi-model oil spill prediction service in the Mediterranean Sea by using well-established oil spill modeling systems and met-ocean forecast forcing data from different sources. The multi-model oil-spill forecasts are available through a unique web where different service scenarios are offered.

In order to assess the MEDESS-4MS services, a series of in situ exercises (hereinafter named "Serious Games (SG)" following the Project terminology) were planned during the course of the project to validate the model performance and its capabilities in different Mediterranean regions. The MEDESS-GIB exercise was one of those MEDESS-4MS $\mathrm{SG}$, the main objective of which was to test the operational oceanographic products and the MEDESS-4MS oil spill forecasting capabilities in the Strait of Gibraltar and the Alboran Sea.

The Strait of Gibraltar is the natural connection between the Mediterranean Sea and the Atlantic Ocean and a choke point of the world ocean, representing an important challenge for the operational oceanographic services. The area is characterized by very strong currents and by a complex dynamics. Furthermore, the Strait of Gibraltar supports a very intense maritime traffic (about 100000 ships in 2013) being a hot area in terms of incidental or voluntary oil spill events, as well as of SAR interventions, including those made by the Spanish Search and Rescue Office (SASEMAR). The MEDESS-GIB campaign, and the resulting data set presented here, foresees to increase our knowledge on the ocean dynamics in such a singular area.

Data provided by this experiment are of great value not only for the characterization of the large-scale dynamics but also to evaluate the ability of numerical models to reproduce the different processes measured during the experiment. Moreover, the number of drifters released as well as the deployment strategy make this experiment unique in this singular area.

The key processes involved in water exchanges through the Strait of Gibraltar, and their extension into the Alboran Sea gyres have been the object of many studies in the past, mainly from moorings, remote-sensing data and hydrographic cruises (e.g., Viudez and Tintore, 1985; Garcia Lafuente et al., 1998; Renault et al., 2012). However, little work has been carried out from a Lagrangian perspective (Sayol et al., 2013). To our knowledge, the first reported Lagrangian experiments using a few surface and deep floats were reported by Gascard and Richez (1985) during the 
MEDIPROD cruises, including some references to previous experiments back to the 1970s.

The following sections describe the MEDESS-GIB and the resulting database, summarizing the campaign objectives and providing details on the drifter deployment plan, the measured Lagrangian trajectories and the pre-processing and quality control procedures applied to build the MEDESSGIB database

\section{The MEDESS-GIB SG: objectives and design}

The main objective of the experiment was to provide the surface velocity field in the Strait of Gibraltar, the Alboran Sea and the Algerian basin from a Lagrangian point of view. Apart from being a very useful data source to measure the surface circulation, the MEDESS-GIB was designed to be an observational reference for the validation of the existing basin scale operational met-ocean and oil-spill models, i.e., the MyOcean IBI-MFC (Sotillo et al., 2015) and localscale systems, i.e., the Puertos del Estado SAMPA highresolution ocean forecast products (Sánchez-Garrido et al., 2013). These operational products are used by the MEDESS4MS multi-model oil spill forecasting service as part of its met-ocean forcing data catalog. Likewise, the MEDESS-GIB data have been useful to test and validate the oil spill forecasting capabilities. More specifically, the MEDESS-GIB SG was designed to provide useful information and data for the following applications and objectives:

- Evaluating the surface dynamics in the area by means of an extensive drifter buoy campaign and assessing the quality of the ocean model data available through the MEDESS-4MS service for the area.

- Increasing knowledge on the dynamics of the study area, taking the opportunity of counting together with multi-model and multi-platform observational data sources (i.e., HF-radar, in situ devices, satellite sensors).

- Assessing MEDESS-4MS services in a real-time exercise, evaluating the different components of the developed system, and identifying through stress tests potential shortcomings for its use in real scenarios.

- Testing the sensitivity of the MEDESS-4MS forecast solution according to both the selected oil spill model (from the five provided by the MEDESS-4MS service) and the met-ocean data used for forcing the simulations.

- Understanding differences between the behavior of the different buoy types and assessing capabilities to simulate their paths (some of the drifters provided information on the $1 \mathrm{~m}$ depth of the water column, whereas others measured only currents in the first few centimeters).
- To produce a HF-radar validation exercise by means of comparing the information provided by a significant number of drifters with the remotely sensed data provided by the PdE HF-radar facility covering the Gibraltar area.

- Reinforcing the existing connections between SASEMAR and the Spanish oceanographic community (represented in the MEDESS-GIB exercise by the Spanish partners of the MEDESS-4MS project).

The MEDESS-GIB experiment was held on 9 September 2014, when 35 buoys were released following the deployment plan shown in Fig. 1a. It was decided that most of the drifters (30 out of the 35) should meet the performance criteria of the CODE drifter (Davis, 1985). This CODE/Davis drifter is a robust solution to acquire coastal and estuarine water currents within a meter of the water surface, minimizing wind drag effects. All the CODE/Davis drifters used in the MEDESS-GIB SG were equipped with a sea surface temperature sensor, GPS receiver and Iridium-based satellite telemetry. They were provided by IMEDEA-UIB-CSIC, ICM-CSIC and Puertos del Estado, and produced by different manufacturers (Innova, DBI, and Metocean, respectively). Two other platforms were also used in the exercise: three ODI Sphere, provided by IMEDEA-UIB-CSIC, and two SPOT with GSM communication, provided by SASEMAR. Wind drag on ODI Sphere buoys was reduced minimizing their area of exposure over sea surface. The SPOT buoys were recovered the same day of their launch, drifting only through the Strait of Gibraltar, therefore these data have not been included in the MEDESS-GIB database. Figure 2 illustrates the drifter buoy types used in the MEDESS-GIB campaign.

The drifter deployment was designed to be as synoptic as possible to get an overall view of the surface circulation covering the whole domain. In order to meet this requirement, deployments were coordinated using four different vessels, three SASEMAR Salvamar SAR units and one auxiliary boat from the Port Authority of Algeciras Bay (APBA) to access the whole targeted region, covering a total area of about $680 \mathrm{NM}^{2}$ in a $6 \mathrm{~h}$ time window (see Fig. 1a).

The in situ operations of MEDESS-GIB SG took place from 9 to 11 September 2014. During these dates, a mixed team composed of scientists and technical experts from all the participating institutions was built and based on the headquarters of the APBA, where a coordination room for the exercise was set up. The first day was mainly dedicated to the drifter deployments, whereas the following days were focused on the real-time monitoring of the initial tracks. This monitoring allowed the identification of potential drifters to be recovered (i.e., buoys beached or too close to land, or in separated flows at risk of beaching). The campaign was coordinated by Puertos del Estado and involved the participation of ICM-CSIC, IMEDEA/UIB-SOCIB, the APBA and SASE- 

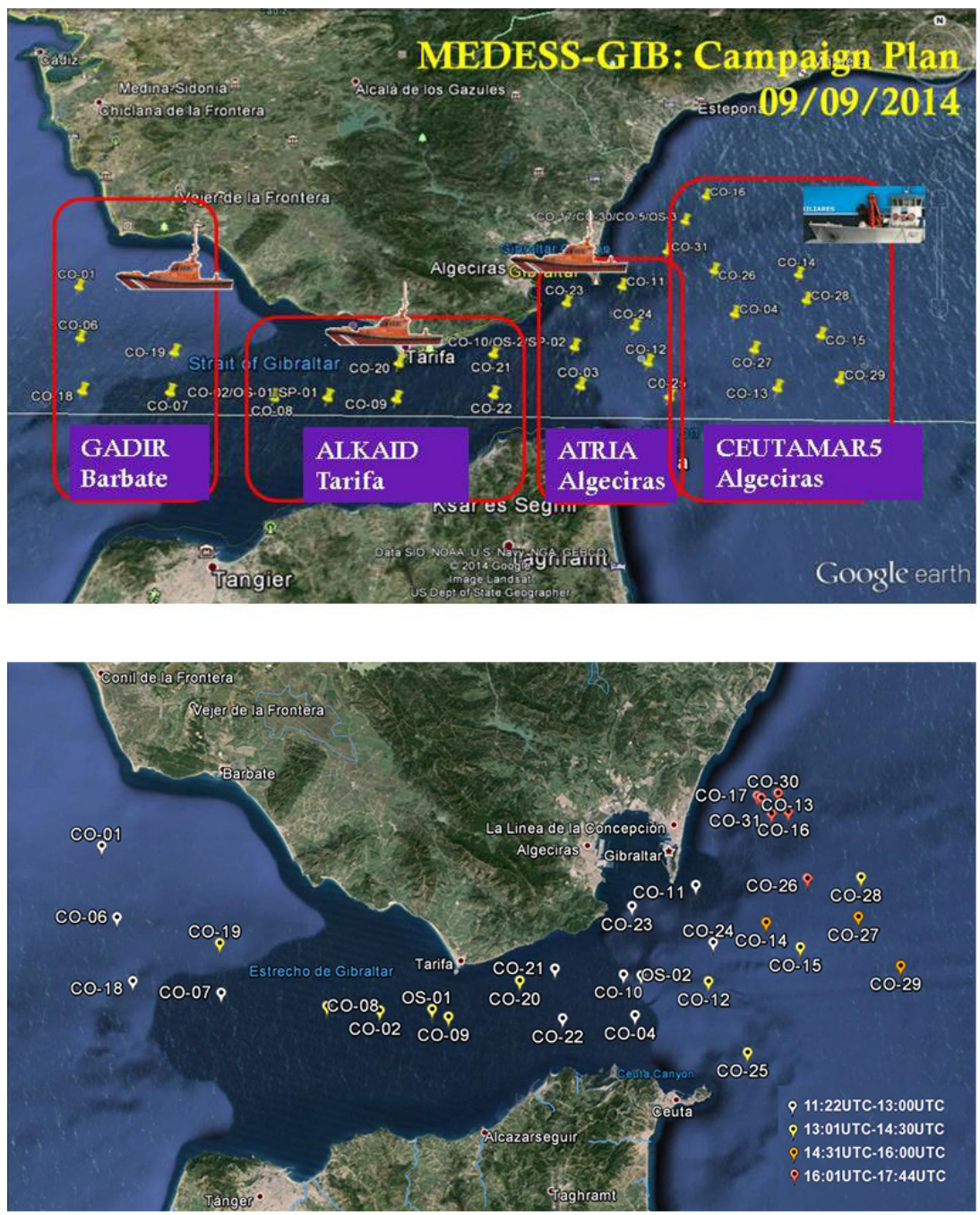

Figure 1. (a) MEDESS-GIB Drifter Buoy deployment survey plan with vessel unit distribution. CODE/Davis drifter buoys marked as CONN. ODI Sphere buoys marked as OS-NN and Spot buoys as SP-NN. (b) Deployment position of the buoys released in the MEDESS-GIB Campaign. A color code is used to show information on the deployment time for each buoy.

MAR, all of them partners or end users of the MEDESS-4MS forecasting services.

\section{The MEDESS-GIB database}

In MEDESS-GIB, each buoy provider was responsible for the reception and pre-processing of the data acquired by their own drifters. Nevertheless, all in situ collected data were available in near real time in a common format adopted by all participants. To this aim, each provider made the required pre-processing and quality control (QC) to deliver data in csv and $\mathrm{kml}$ standard formats and unified file-naming conventions.

\subsection{Quality control and generation of different data product levels}

Pre-processing involves QC procedures to detect and identify wrong or invalid data prior to provide the whole data set. They have been divided into three basic steps: raw data collection, QC process and a final product including the velocity derived from trajectories, designed as L0, L1 and L2, respectively.

L0 product was designed to compile raw decoded data as it was transmitted through the communications system. As noted above, all devices incorporated Iridium communications system, which encodes data into a file message (denoted as short bus data file, sbd) in binary format.

In designing the $\mathrm{QC}$ applicable to data provided by drifting devices, mainly two types of problems commonly arise: the presence of spikes and bad data from both the geoloca- 


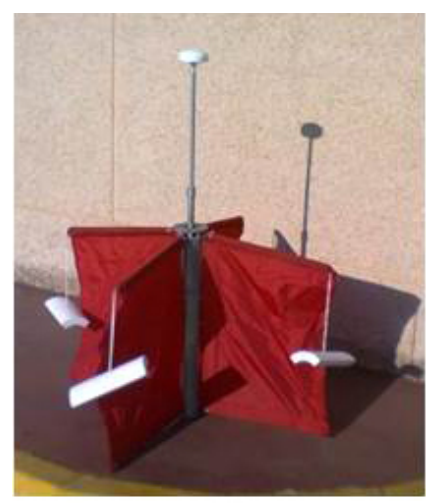

(a)

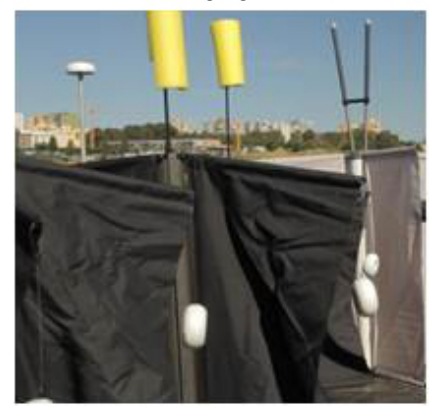

(c)

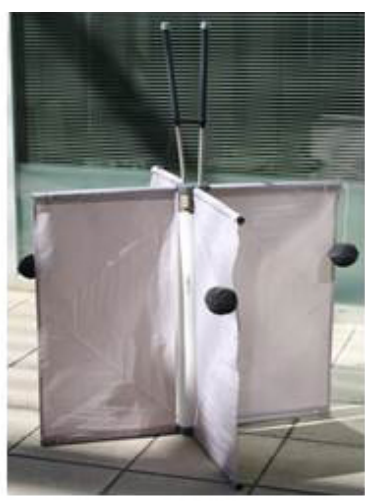

(b)

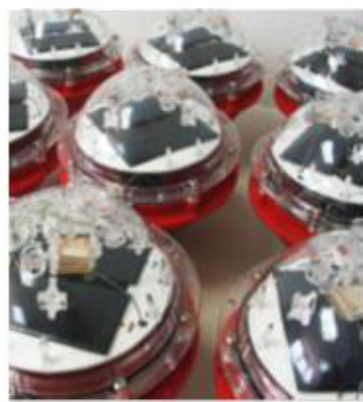

(d)
Figure 2. The in situ drifter buoy platforms used in the MEDESSGIB Campaign: (a) MetOcean I-SLDMB CODE drifter (provided by Puertos del Estado) (b) DBI CODE drifter (provided by ICMCSIC) (c). Albatros CODE/Davis drifter (provided by IMEDEA); ODI Sphere drifter (provided by IMEDEA).

tion system and the carried sensors. In MEDESS-GIB experiment all drifters carried temperature sensors. According to specified criteria, each individual record is qualified with a flag value that characterizes its status after the QC procedure. Table 1 provides the flag scale used for producing the MEDESS-GIB data set, which is analogous to the one developed for the marine Copernicus services (http: //marine.copernicus.eu/) and the Groom project (http://www. groom-fp7.eu, SOCIB, 2014), and a subset of the flag scale adopted by the international ARGO program (Table 2, page 77 in Carval et al., 2014).

As a general rule, a datum is considered "bad" if it has no physical interpretation or considerably exceeds a range of valid values for such magnitude. This range can be absolute, as in the case of latitude and longitude values which should be imperatively within the range $\left(-90^{\circ}, 90^{\circ}\right)$ and $\left(-180^{\circ}\right.$, $180^{\circ}$ ), respectively or, it may be established according to physical assumptions (for example, $70^{\circ} \mathrm{C}$ is a correct value for a water temperature record while not being valid for sea surface temperatures; in this experiment a range of $\left(10^{\circ}, 40^{\circ}\right)$ has been considered; see Table 2).

A second aspect is the presence of spikes. Spikes may be inside or outside the valid range, but their most characteris-
Table 1. Flag scale used in QC procedures.

\begin{tabular}{ll}
\hline Flag & Category \\
\hline 0 & No check applied \\
1 & Good data \\
2 & Probable good data \\
3 & Probably bad data \\
4 & Bad data \\
6 & Spike \\
8 & Interpolated data \\
9 & Missing data \\
\hline
\end{tabular}

tic trait is that they exhibit a sudden change with respect to the neighboring values. In this case, the record is flagged as a spike, but not necessarily considered as bad data. The test applied makes use of the spike definition based on three-point criteria:

$\operatorname{spike}(t)=$

$\left|\mathrm{x}(\mathrm{t})-\frac{\mathrm{x}(\mathrm{t}+1)+\mathrm{x}(\mathrm{t}-1)}{2}\right|\left|\frac{\mathrm{x}(\mathrm{t}+1)-\mathrm{x}(\mathrm{t}-1)}{2}\right|$,

where $t$ denotes time or a counter and $x(t)$ represents any variable to be checked. Table 2 lists the valid ranges and spike thresholds considered for each checked variable: geolocation, temperature and speed. While latitude and longitude data should lie within an absolute range of validity, range intervals and spike values for the rest of variables must be tuned to the characteristic features of the explored region. Since the MEDESS-GIB experiment has been developed in the Gibraltar area in September, we do not expect very low values of sea water temperature. On the contrary and due to the dynamics, we can expect relatively intense sea surface ocean currents.

Because velocities are not directly measured but computed from drifter tracks, tests of valid range over the velocities are necessary to detect anomalous drifting, usually registered over a certain period of time. Such abnormal behavior can be due to, for example, a drifter that has been picked up by some boat or has been trapped or dragged by some fishnet or helix. Instead, velocity spikes are mostly related to geolocation spikes; even though providing realistic values of latitude and longitude (that is, within their valid range) a wrong calibration of the GPS can lead to a significant velocity spike. In this case the spike test for speeds should automatically mark with spike flags the latitude and longitude of such record. If a spike is presented in the drifter geolocation, the scheme of velocity derivative may produce wrong velocity values at the border of the spike while the value at the spike itself may be tagged as good data. To circumvent it we have applied a two-step procedure using backward and upward differences before computing the velocities (Hansen and Poulain et al., 1996). Thus, records adjacent to a spike switch from "good" to "bad" at each pass while the spike itself remains tagged 
Table 2. Ranges, spike thresholds and flag categories used to characterize the quality of individual records.

\begin{tabular}{lll}
\hline Variable & Range/Spike & Flag \\
\hline Temp. $\left({ }^{\circ} \mathrm{C}\right)$ & $\left(10^{\circ}, 40^{\circ}\right)$ & 4 \\
& $\geq 2^{\circ}$ & 6 \\
Latitude & $\left(-90^{\circ}, 90^{\circ}\right)$ & 4 \\
Longitude & $\left(-180^{\circ}, 180^{\circ}\right)$ & 4 \\
Speed $\left(\mathrm{m} \mathrm{s}^{-1}\right)$ & {$[0.0,4.0]$} & 2 \\
& {$[3.0,4.0]$} & 4 \\
& $\geq 2.5$ & 6 \\
\hline
\end{tabular}

as "bad" in both passes, therefore allowing to easily identify geolocation errors.

As a result, the application of all these $\mathrm{QC}$ procedures to each record constitutes the $\mathrm{L} 1$ product.

\subsection{Computing the velocities and cutting time series}

The $\mathrm{L} 2$ product proceeds with the final computation of velocities and extracting or cutting the time series in several temporal segments defined by redeployments or other circumstances (i.e., the case of buoys temporarily trapped or beached in coastal areas and structures that reincorporate again into the mean flow). To compute the velocity several schemes can be adopted (upward, backward, centered, etc.), including several terms around a given point to reduce truncation errors or to perform more complex algorithms (adjusting splines, filters, etc.). Due to the relatively high sampling frequency used in this MEDESS-GIB SG, the velocity fields are computed by direct finite differencing the drifter fixes without any previous filtering. We have adopted a symmetrized combination of the backward and forward operators for the space derivative, such as

$v(t)=\frac{x(t+1)-x(t-1)}{2 \Delta t}+O\left(\Delta t^{2}\right)$,

resulting in a second-order scheme in time. This scheme is more precise than those based on backward and forward differences and is suitable to produce reasonable values at points with spikes. If a geolocation with spike (in latitude, longitude or at both) is found at a given $t$, the scheme computes the velocity at points adjacent to the spike using $x(t-1)$ and $x(t+2)$ and $x(t-2)$ and $x(t+1)$ values for each border respectively. Distances should be computed with a WSG-84 ellipsoidal model of the Earth (i.e., Karney, 2013). However, given the high resolution of the transmitted data, the distance between consecutive points are rather small and therefore negligible differences in the computation of velocities are found using rather a spherical or planar approximation.

Finally, care has to be taken at the beginning of the time series by using the information deployment. Some drifter models trigger the communication system once the drifter is in water while others just follow a pre-determined clock cycle after manual activation. In this case we have considered the time and location of the deployment as the first valid record flagging the temperature with a missing value $(-999$, flag $=9)$. For the velocity of such records the centered scheme described above is replaced by a forward and backward scheme. The final L2 product stores the velocity values in components $(u, v)$, the commonly adopted oceanographic convention (east-north coordinate system).

\subsection{Data files and formats}

Data filename convention and format were adopted to facilitate the exchange among participants without the need of any particular software. The file name convention follows the structure:

\section{MEDGIB-XXXX_xx_yy_LX_YYY.csv,}

where each field corresponds to the following: XXXX: descriptor of the buoy model (CODE, ODIS, SPOT). xx: a twodigit identifier of the drifter number (from 01 to 35). yy: a two-digit counter of the number of separate tracks for a given drifter $(01, \ldots)$. LX : a one-digit counter identifying the product level (L0, L1 and L2). YYY: a three-character field identifying the drifter provider (i.e., PdE, ICM, IME).

As an example, MEDGIB-CODE_11_02_L2_ICM.csv is the $\mathrm{L} 2$ product corresponding to the second track $(02)$ of the drifter number 11, of CODE type and belonging to the ICM.

The adopted data format consists of standard plain text displayed in columns separated by commas, popularly known as csv format. However, the data format depends on the preprocessing level, since L0 data contains more information than L1 and L2.

The follow line illustrates the format of L2 product:

$300234061566400,2014,9,9,17,35,3,35.9443$,

$-5.1517,17.876,64,-53,1,1,1,1$,

where the first number is the IMEI (unique Iridium modem identifier of the drifter communication system); the following six fields correspond to the date of the message (year, month, day, hour, minute and second); the next three float fields are the latitude, longitude and temperature $\left({ }^{\circ} \mathrm{C}\right)$; the next two digits correspond to $u$ and $v$ components of velocity in $\mathrm{cm} / \mathrm{s}$ and the final four integer values indicate the QC flag of latitude, longitude, temperature and speed data.

\section{Overview of the MEDESS-GIB drifter buoy trajectories and SST data}

The inflow of Atlantic waters through the Strait of Gibraltar is characterized by strong velocities, that when combined with the topography of the Alboran basin develop a subcritical flow, which evolves into the permanent anticyclonic gyres (see Fig. 3 from Sánchez-Garrido et al., 2013). Further east, 


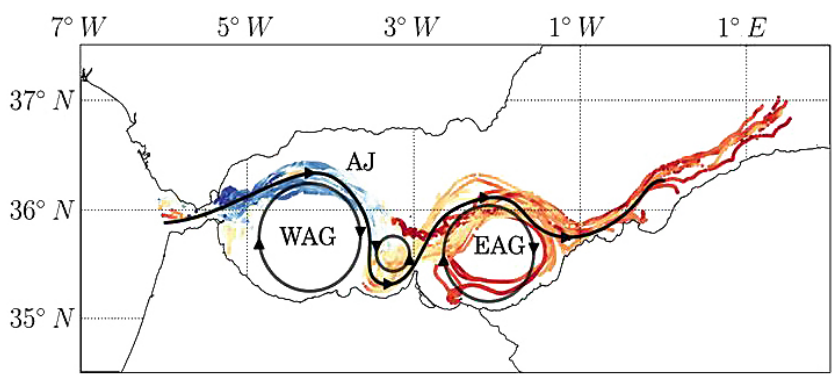

Figure 3. Sketch of the classical surface circulation of the Alboran Sea adapted from Sanchez-Garrido et al. (2013) with the MEDESSGIB drifters superimposed. Contours represent stream lines. The Atlantic jet (AJ), the Western (WAG), and Eastern (EAG) Alboran gyres are labeled.

the Almeria-Oran front separates two water masses (the recent fresh Atlantic water and the saltier Mediterranean water), impinging on the African coast and leading the flow of recent Atlantic waters to progress eastwards, establishing the so-called Algerian Current, which flows eastwards mainly along the African coast. Although less frequent, new Atlantic waters have also been detected entering through the Ibiza Channel northwards (Sayol et al., 2013). Moreover, strong tidal effects at the entrance of the Strait together with the wind effect (mainly westerlies and easterlies) configure a very complex picture of the surface currents which has always been a challenging issue for modeling purposes.

The path of the MEDESS-GIB drifters quite accurately depicts this classical structure of the main surface circulation at the Strait of Gibraltar and the adjacent Alboran Sea. For instance, Fig. 4 shows the drifter tracks for three different times providing a close picture of all these features. During the first days, most of drifters traveled eastwards following the Atlantic jet (AJ), as would be expected for buoys deployed in this area (see Fig. 4a). Some of them, mainly those occupying the peripheral positions, re-circulated at both sides of the AJ in nearby areas of the Strait. Drifters that directly followed the AJ covered the northern side of the Western Alboran Gyre (WAG) after 4 days (Fig. 4a). Most of the buoys, after impinging on the African coast, in the surroundings of Cape Three Forks, continued moving eastwards along the northern branch of the Eastern Alboran Gyre (EAG, Fig. 4b). At the end of their drift along the EAG, the buoys moved southward depicting with their trajectories the Almeria-Oran frontal structure. In contrast to the trajectories around the WAG, where none of the drifters made a closed loop, some of them looped around the EAG, even traversing northward the Alboran basin towards the Spanish coast. However, most of them continued further eastward along the African slope following the Algerian Current.

The complete evolution of the MEDESS-GIB drifters is shown in Fig. 4c. Some drifters in the Algerian Current left the main current and deflected to the northeast affected by in-
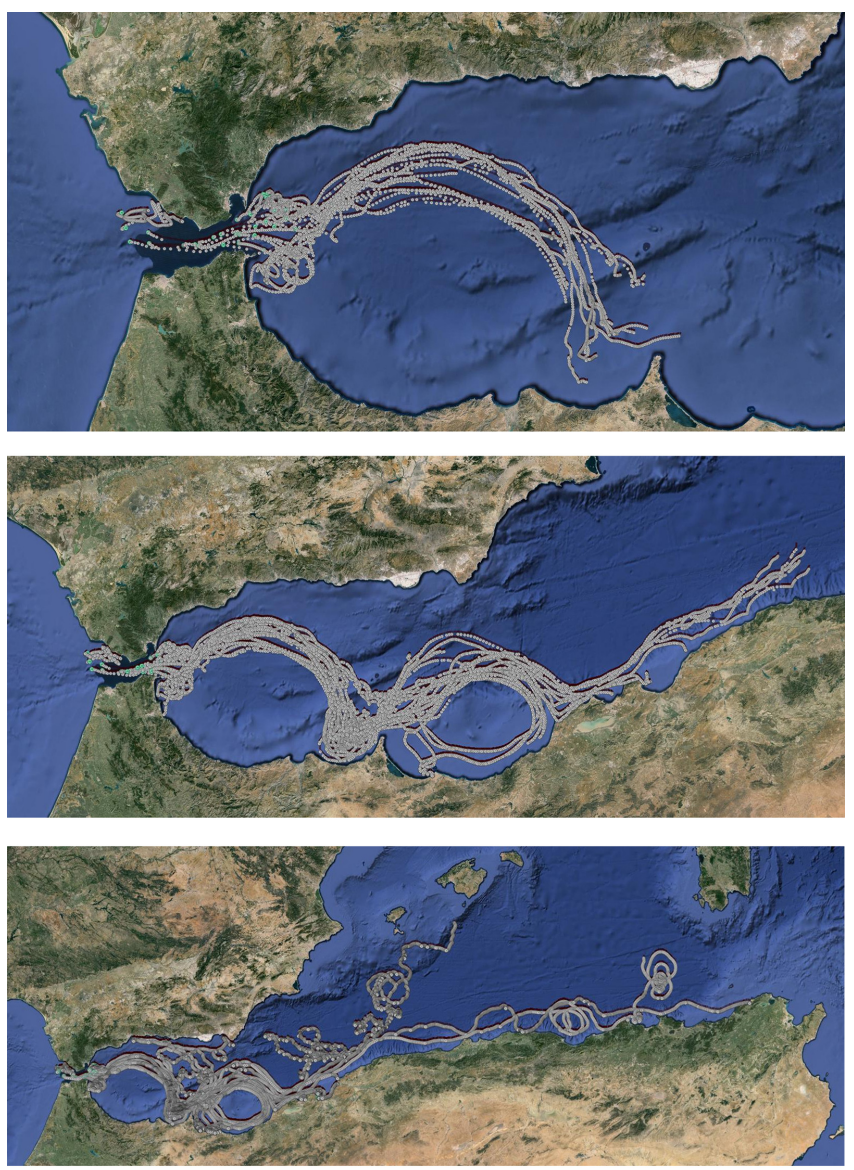

Figure 4. Trajectories of the MEDESS-GIB drifter buoys at different dates after deployment: (a) 9/13/2015 (+4 days), (b) 9/25/2015 (+14 days), (c) 12/9/2015 (+91 days).

ertial or (sub)mesoscale motions arriving up to the Balearic shelf. At this point, it should be mentioned that the intrusion of modified Atlantic waters into the northwestern basins is a very active research area due to the importance of this water exchange in the biogeochemical processes of the western Mediterranean Sea (Balbín et al., 2013). A few units completed the eastward drift of the Algerian Current revealing some eddy-like instabilities. One drifter reached the Tunisia coast and beached before getting into the Strait of Sicily, whereas another one detached from the current and performed several loops indicating the presence of an anticyclonic eddy, probably generated by instability in the Algerian Current.

It is also worth mentioning that the buoys that later reached the transitional area between the WAG and the EAG (mostly those initially not following the AJ at the Strait of Gibraltar which, instead, spent some time recirculating around its nearby areas) did not move directly to the EAG, but started some cyclonic circulation and moved towards the Iberian coast. The different behavior of this subset of buoys may be linked to the temporal prevalence of surface easterlies, block- 


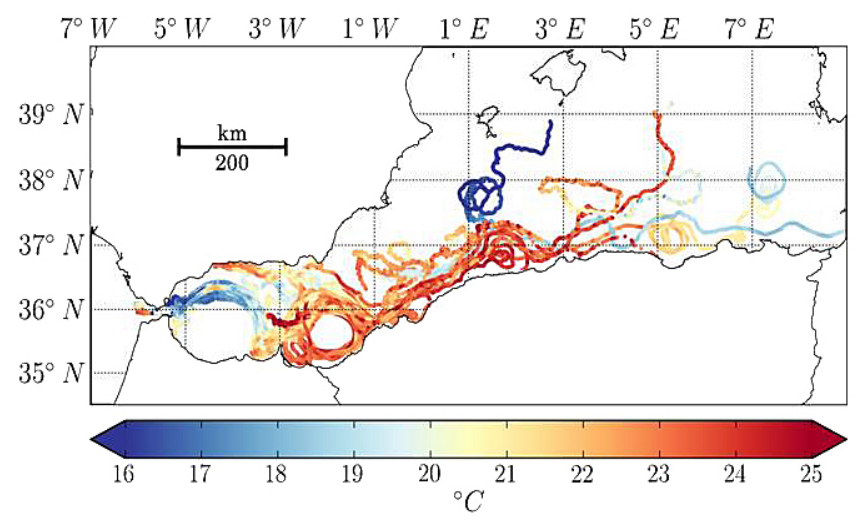

Figure 5. SST values measured along track from the MEDESSGIB-SG Buoys. Evolution of the buoys until 12/9/2014 (+91 days after deployment).

ing the eastward drift. Eventually, some of them returned to the main flow passing again through the WAG and the EAG.

Finally, it should be pointed out that the MEDESS-GIB database presented here not only contains the Lagrangian positions and their corresponding velocities but also includes observed SST data. All the MEDESS-GIB Code/Davis and ODI buoys carried a thermometer, and along track in situ SST measurements were collected to reveal the water masses transformation. Figure 5 depicts the Lagrangian SST picture obtained during the 91 days of buoys drift. It can be seen that the cold waters of the strait which rapidly advected around the WAG appear to slowly warm as they reach Cape Three Forks. Then, those drifters that either looped around the EAG or progressed to the east along the Algerian Current eventually warmed about $6-7^{\circ} \mathrm{C}$ when reaching $3^{\circ} \mathrm{E}$. Those that progressed further to the east appear to have a remarkably colder SST, probably coinciding with the general cooling period of November.

\section{Summary}

To the author's knowledge, the MEDESS-GIB campaign, developed in the framework of the EU MED Program MEDESS-4MS project, is the most important quasi-synoptic drifter deployment in the Mediterranean Sea, and provides the most complete Lagrangian view of the Atlantic water inflow through the Strait of Gibraltar.

The MEDESS-GIB data set is available through the PANGAEA (Data Publisher for Earth and Environmental Science) repository, with the following doi:10.1594/PANGAEA.853701. Likewise, the MEDESSGIB quality-controlled data will be incorporated as part of the Copernicus Marine historical products. The data set is organized following a three-level criteria (i.e., L0, L1 and L2), with the more comprehensive quality-controlled L2 data including the Lagrangian-derived velocities being available to users.
The autumn-winter Lagrangian observations obtained during the MEDESS-GIB experiment allowed us to get a detailed picture of the surface circulation of Atlantic waters and its transformation from the Strait of Gibraltar through the Alboran Sea and along the African coast. To conclude, the presented MEDESS-GIB database is a valuable data set to support ongoing and further studies on the surface circulation patterns in the Alboran Sea, as well as on connectivity processes with the Northwestern and the Algerian Current basins.

Acknowledgements. The MEDESS-GIB experiment was performed as part of the MEDESS-4MS Project activities (Project ref. 2S-MED11-01), supported by the European Regional Development Fund in the framework of the MED Programme. D. Conti is currently a $\mathrm{PhD}$ fellowship (FPI/1543/2013) granted by the Conselleria d'Educació, Cultura i Universitats from the Government of the Balearic Islands co-financed by the European Social Fund. J. M. Sayol is thankful for the financial support of CSIC and FSE with the JAE-pre PhD scholarship program. The authors thank the following people for their great contribution and help during the campaign: Rocio García and Carlos Elgarbay from the APBA; Justino Martinez, Jose Antonio Pozo and Kintxo Rodriguez from ICM-CSIC; Arancha Lana from IMEDEA; the SOCIB technical Data Center Service; Roland Aznar, Susana Perez, and Juan Jose Melones from Puertos del Estado; Diego Belmonte and Andres Collado from Velum; the crews of the SASEMAR ATRIA, GADIR, ALKAID, Adolfo Serrano and the staff from the SASEMAR CCS Tarifa Centre.

Edited by: G. M. R. Manzella

\section{References}

Al-Rabeh, A.: Estimating surface oil spill transport due to wind in the Arabian Gulf, Ocean Eng., 21, 461-465, 1994.

Balbín, R., López-Jurado, J. L., Flexas, M. M., Reglero, P., VélezVelchí, P., González-Pola, C., Rodríguez, J. M., García, A., and Alemany, F.: Interannual variability of the early summer circulation around the Balearic Islands: Driving factors and potential effects on the marine ecosystem, J. Marine Syst., 138, 70-81, 2013.

Barron, C. N., Smedstad, L. F., Dastugue, J. M., and Smedstad, O. M.: Evaluation of ocean models using observed and simulated drifter trajectories: Impact of sea surface height on synthetic profiles for data assimilation, J. Geophys. Res., 112, C07019, doi:10.1029/2006JC003982, 2007.

Bellomo, L., Griffa, A., Cosoli, S., Falco, P., Gerin, R., Iermano, I., Kalampokis, A., Kokkini, Z., Lana, A., Magaldi, M. G., Mamoutos, I., Mantovani, C., Marmain, J., Potiris, E., Sayol, J. M., Barbin, Y., Berta, M., Borghini, M., Bussani, A., Corgnati, L., Dagneaux, Q., Gaggelli, J., Guterman, P., Mallarino, D., Mazzoldi, A., Molcard, A., Orfila, A., Poulain, P.-M., Quentin, C., Tintoré, J., Uttieri, M., Vetrano, A., Zambianchi, E., and Zervakis, V.: Toward an integrated HF radar network in the Mediterranean Sea to improve search and rescue and oil spill response: 
the TOSCA project experience, J. Oper. Oceanogr., 8, 95-107, doi:10.1080/1755876X.2015.1087184, 2015.

Capó, E., Orfila, A., Sayol, J. M., Juza, M., Sotillo, M. G., Conti, D., Simarro, G., Mourre, B., Gómez-Pujol, L., and Tintoré, J.: Assessment of operational models in the Balearic Sea during a MEDESS-4MS experiment, accepted, Deep-Sea Res. Pt. II, 2016.

Carval, T., Keeley, B., Takatsuki, Y., Yoshida, T., Loch, S., Schmid, C., Goldsmith, R., Wong, A., McCreadie, R., Thresher, A., and Tran, A.: Argo user's manual V3.2 doi:10.13155/29825, 2014.

Davis, R. E.: Drifter observations of coastal surface currents during CODE: The method and descriptive view, J. Geophys. Res., 90, 4741-4755, 1985

DeDominicis, M., Pinardi, N., Zodiatis, G., and Archetti, R.: MEDSLIK-II, a Lagrangian marine surface oil spill model for short-term forecasting - Part 2: Numerical simulations and validations, Geosci. Model Dev., 6, 1871-1888, doi:10.5194/gmd-61871-2013, 2013.

GCOS (Global Climate Observing System): Implementation plan for the global observing system for climate in support of the UNFCCC (2010 update), GCOS Rep., 138, 186 pp., 2010.

García-Ladona, E., Font, J., del Río, E., Julià, A., Salat, J., Chic, O., Orfila, A., Àlvarez, A., Basterretxea, G., Vizoso, G., Piro, O., Tintoré, J., Castanedo, S., Gil-Coto, M., and Herrera, J. L.: The use of Surface Drifting floats in the monitoring of oil spills. The Prestige case, Proceedings of the 19th International Oil Spill Conference (IOSC), 2005.

Garcia Lafuente, J., Cano, N., Vargas, M., Rubin, J., P., and Hernandez-Guerra, A. Evolution of the Alboran Sea hydrographic structures during july 1993, Deep-Sea Res., 45, 39-65, 1998.

Gascard, J. C. and Richez, C.: Water masses and circulations in the Western Alboran Sea and in the Straits of Gibraltar, Prog. Oceannogr., 15, 157-216, 1985.

Hansen, D. V. and Poulain, P. M.: Quality control and interpolations of WOCE-TOGA drifter data, J. Atmos. Oc. Technol., 13, 900909, 1996.

Karney, Ch. F. F: Algorithms for Geodesics, J. Geodesy, 87, 43-55, 2013

Liu, Y. And Weisberg, R. H.: Evaluation of trajectory modelling in different dynamic regions using normalized cumulative lagrangian separation, J. Geophys. Res., 116, C0913, doi:10.1029/2010JC006837, 2011.

Lorente, P., Piedracoba, S., and Alvarez-Fanjul, E.: Calibration and Validation of High-Frequency Radar Ocean Surface Current Observations in the NW of the Iberian Peninsula, Cont. Shelf Res., 92, 1-15, 2015.

Lumpkin, R. and Pazos, M.: Measuring surface currents with Surface Velocity Program drfiters: the instrument, its data, and some recent results, in: Lagrangian Analysis and Predictions of Coastal and Ocean Dynamics, edited by: Griffa, A., de Kirwan Jr., A., Mariano, A., Özgökmen, T., and Rossby, T., Cambridge University Press, ISBN: 139780521870184, 2007.

Molcard, A., Poulain, P. M., Forget, P., Griffa, A., Barbin, Y., Gaggelli, J., De Maistre, J. C., and Rixen, M.: Comparison between VHF radar observations and data from drifter clusters in the Gulf of La Spezia (Mediterranean Sea), J. Mar. Syst., 78, S79-S89, 2009.
Ohlmann, C., White, P., Washburn, L., Terril, E., Emery, B., and Otero, M.: Interpretation of coastal HF radar-derived currents with high-resolution drifter data, J. Atmos. Ocean. Technol., 24, 666-680, 2007.

Poulain, P.-M., Bussani, A., Gerin, R., Jungwirth, R., Mauri, E., Menna, M., and Notarstefano, G.: Mediterranean surface currents measured with drifters: From basin to subinertial scales, Oceanography, 26, 38-47, 2013.

Price, J. M., Reed, M., Howard, M. K., Johnson, W. R., Ji, Z. G., Marshall, C. F., Guinasso, N. L., and Rainey, G. B.: Preliminary assessment of an oil-spill trajectory model using satellite tracked, oil-spill-simulating drifters, Environ. Model. Softw., 21, 258-270, 2006.

Rossby, T.: Evolution of Lagrangian methods in oceanography, in: Lagrangian Analysis and Predictions of Coastal and Ocean Dynamics, edited by: Griffa, A., de Kirwan Jr., A., Mariano, A., Özgökmen, T., and Rossby, T., Cambridge University Press, ISBN: 139780521870184, 2007.

Reed, M., Turner, C., and Odulo, A.: The role of wind and emulsification in modelling oil spill and surface drifter trajectories, Spill Sci. Technol. Bull., 1, 143-157, 1994.

Renault, L., Oguz, T., Pascual, A., Vizoso, G., and Tintore, J.: Surface circulation in the Alborán Sea (western Mediterranean) inferred from remotely sensed data, J. Geophys. Res., 117, C08009, doi:10.1029/2011JC007659, 2012.

Sayol, J. M., Orfila, A., Simarro, G., López, C., Renault, L., Galán, A., and Conti, D.: Sea surface transport in the Western Mediterranean Sea: a Lagrangian perspective, J. Geophys. Res., 118, 6371-6384, 2013.

Sayol, J. M., Orfila, A., Simarro, G., Conti, D., Renault, L., and Molcard, A.: A Lagrangian model for tracking surface spills and SaR operations in the ocean, Environ. Modell. Software, 52, 74 82,2014

Sánchez-Garrido, J. C., Lafuente, J. G., Álvarez, E., Sotillo, M. G., and de los Santos, F. J.: What does cause the collapse of the Western Alboran Gyre? Results of an operational ocean model, Prog. Oceanogr., 116, 142-153, 2013.

Shadden, S. C., Lekien, F., Paduan, J. D., Chavez, F. P., and Marsden, J. E.: The correlation between surface drifters and coherent structures based on high-frequency radar data in Monterey Bay, Deep-Sea Res. Pt. II, 56, 161-172, 2009.

Sotillo, M. G., Alvarez Fanjul, E., Castanedo, S., Abascal, A. J., Menendez, J., Emelianov, M., R., Olivella,García-Ladona, E., Ruiz-Villarreal, M., Conde, J., Gómez, M., Conde, P., Gutierrez, A. D., and Medina, R.: Towards an operational system for oil spill forecast in Spanish coastal waters: initial development and implementation test, Mar. Pollut. Bull., 56, 686-703, 2008.

Sotillo, M. G., Cailleau, S., Lorente, P., Levier, B., Aznar, R., Reffray, G., Amo-Baladrón, A., Chanut, J., Benkiran, M., and Alvarez-Fanjul, E.: The MyOcean IBI Ocean Forecast and Reanalysis Systems: Operational products and roadmap to the future Copernicus Service, J. Oper. Oceanogr., 8, 63-79, doi:10.1080/1755876X.2015.1014663, 2015.

Viudez, A. and Tintore, J.: Time and space variability in the eastern Alboran Sea from March to May 1990, Journ. Geophys. Res., 100, 8571-8586, 1985. 